DOI: 10.36910/6775-2524-0560-2019-37-16

УДК 621.311.69:681.586.7

${ }^{1}$ М. Г. Томенко, ${ }^{1}$ В. І. Томенко, ${ }^{2}$ О. О. Корецька,

${ }^{1}$ Черкаський інститут пожежної безпеки імені Героїв Чорнобиля Національного університету

цивільного захисту України

${ }^{2}$ Чорноморський національний університет імені Петра Могили

\title{
ВИЗНАЧЕННЯ НА РАННІХ СТАДІЯХ АВАРІЙНИХ СИТУАЦІЙ ПОТЕНЦІЙНО НЕБЕЗПЕЧНИХ ВИРОБНИЦТВ ЗА РАХУНОК ФІКСАЦІЇ ЗМІН В ВІБРАЦЇ̈ ОБЛАДНАННЯ
}

Томенко М. Г., Томенко В. І., Корецька О. О. Визначення на ранніх стадіях аварійних ситуацій потенційно небезпечних виробництв за рахунок фіксації змін в вібрації обладнання. В статті розглядаються можливість визначення аварійності технологічного обладнання на ранніх стадіях за рахунок фіксації змін вібрацій при роботі обладнання. Для цього в роботі розглянуто використання консольних п’єзоперетворювачів на базі асиметричних біморфних п’єзоелементів, причому найбільшу увагу приділено визначенню лінійних розмірів та форм таких перетворювачів для побудови ефективних систем фіксації зміни вібраційної картини роботи обладнання. Розроблені макети, проведені експериментальні дослідження, отримано рекомендації по розробці п’єзоперетворювачів для систем раннього визначення аварійних ситуацій.

Ключові слова: аварійні ситуації, консольні доменно-дисипативні п'єзоперетворювачі, ідентифікація обладнання

Форм. 1. Рис. 6. Літ. 10.

Томенко М. Г., Томенко В. И., Корецкая А. О. Определение на ранних стадиях аварийных ситуаций потенциально опасных производств за счет фиксации изменений в вибрации оборудования. В статье рассматриваются возможности определения аварийности технологического оборудования на ранних стадиях за счет фиксации изменений вибраций при работе оборудования. Для этого в работе рассмотрено использование консольных пьезопреобразователей на базе асимметричных биморфных пьезоэлементов, причем наибольшее внимание уделено определению линейных размеров и форм таких преобразователей для построения эффективных систем фиксации изменения вибрационной картины работы оборудования. Разработанные макеты, проведены экспериментальные исследования, получены рекомендации по разработке пьезопреобразователей для систем раннего определения аварийных ситуаций

Ключевые слова: аварийные ситуации, консольные доменно-диссипативные пьезопреобразователи, идентификация оборудования

Форм. 1. Рис. 6. Лит. 10.

Tomenko M.G., Tomenko V.I., Koretska O.O. Identification of potentially hazardous production at the early stages of emergency situations by recording changes in equipment vibration. The article discusses the possibility of determining the accident rate of technological equipment in the early stages by recording changes in vibration during operation of the equipment. For this purpose, the use of cantilever piezoelectric transducers based on asymmetric bymorph piezoelectric elements was considered, with the greatest attention paid to determining the linear dimensions and shapes of such transducers to build effective systems for recording changes in the vibrational pattern of equipment operation. Designed models, conducted experimental studies, received recommendations on the development of piezoelectric transducers for early detection systems for emergency situations.

Keywords: emergency situations, cantilever domain-dissipative piezoelectric transducers, equipment identification

Form 1. Fig. 6. Lit. 10.

Постановка проблеми. В більшості випадків аварії на потенційно-небезпечних об’єктах виникають в наслідок порушення технологічного процесу через поломку обладнання або недбале управління, тобто через людський фактор. В таких випадках аварія, як правило, не відбувається миттєво - їй передують деякі зміни в роботі обладнання, які можуть бути визначені на ранніх стадіях, наприклад - зміна параметрів вібрації. Зміна в роботі обладнання призводить до змін струмів, механічних обертів тощо, що супроводжується зміною технічних параметрів окремих елементів, зміною механічних коливань агрегатів тощо, що можна визначити за допомогою відповідного обладнання. Наприклад, на рис. 1 наведений приклад використання вібродатчика на основі п’єзоперетворювача Volture на коливній платформі [1].

Фіксація відхилень в вихідному струмі п’єзоперетворювача слугує показником порушення функціонування контролюємого обладнання за рахунок визначення зміни вібраційної картини.

Таким чином, попередження виникнення аварійних ситуацій та аварій на ранніх стадіях в технологічних процесах, пов'язаних 3 хімічною, радіаційною та пожежовибухонебезпекою, $\epsilon$ важливим питанням в запобіганні виникненню та ліквідації наслідків надзвичайних ситуацій техногенного характеру $[7,8]$.

Аналіз останніх досліджень і публікацій. В якості таких датчиків визначення механічних відхилень (включаючи вібрацію) в роботі обладнання найчастіше використовують п’єзокерамічні 
перетворювачі (ПП) [6, 9]. Проте при такому методі фіксацій в відхиленні роботи обладнання виникає декілька технічних питань, одним 3 яких $є$ підвищення чутливості датчиків для фіксації малих відхилень вібрацій.

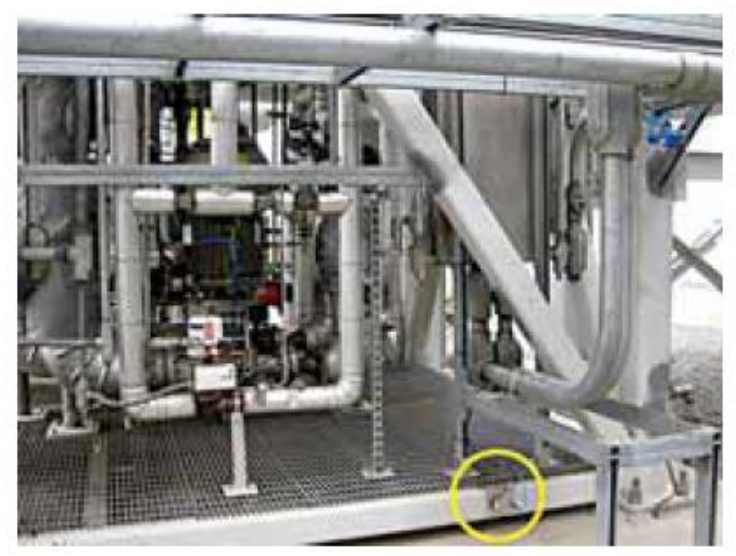

\section{Рис. 1. Закріплений п'єзодатчик вібрації Volture на коливній платформі [1]}

Для цього авторами запропоновано використання п’єзодатчиків вібрації у вигляді консольних доменно-дисипативних п'єзокерамічних перетворювачів (КДПП) $[2,3,5]$. Збільшення чутливості за рахунок використання доменно-дисипативних властивостей п'єзоелементу, коли вектор напруженості поля вихідного сигналу практично перпендикулярний вектору поляризації кераміки, можна досягти зміною форм електродів на сторонах п'єзоелемента.

Проте варіантів виконання таких перетворювачів безліч, які відрізняються різною формою та розмірами як ПП, так і біморфної і консольної пластини. Отже метою даної роботи $є$ визначення лінійних розмірів та форм консольних п’єзокерамічних перетворювачів, що може бути використане в системі визначення аварійних ситуацій потенційно небезпечних виробництв за рахунок фіксації зміни вібраційної картини роботи обладнання.

Основні результати дослідження. Рівень вихідного сигналу ПП залежить не тільки від значень електричних і пружних п'єзоконстант, а й від просторового співвідношення векторних величин: $\mathbf{P}$ вектора поляризації, $\mathbf{F}$ - вектора сили, що впливає на ПП та $\mathbf{E}$ - вектора напруженості поля між вихідними електродами. При перпендикулярному розташуванні векторів $\mathbf{P}$ та $\mathbf{E}$ (доменно-дисипативний ефект) можна досягти більшої чутливості п’єзоелемента, ніж при їх традиційному паралельному розташуванні [9].

Для визначення рівня вихідного сигналу КДПП в залежності від розміщення вихідних електродів, тобто від кута $\delta$ між векторами $\mathbf{P}$ i $\mathbf{E}$, була отримана залежність значення п'єзомодуля $\mathrm{d}_{31}$ від кута $\delta$ і механічних напруг [4]:

$$
d_{31}=d_{31}^{(0)}-\frac{2}{\pi^{2}} \int_{0}^{\frac{1}{4} \sin (\delta)} \mathrm{d} \delta \cdot\left(X_{1} \cos ^{2}(\delta)+Y_{1}\right) \sqrt{\sin ^{2}(\delta)-\cos ^{2}(\delta)} \times \arcsin \sqrt{\frac{\cos ^{2}(\delta)-\sigma_{p}}{1-\cos ^{2}(\delta)}},
$$

де $\sigma_{\mathrm{p}}=\sigma_{\mathrm{c}} / \sigma, \sigma-$ механічна напруга на біморфному ПП; $\sigma_{\mathrm{c}}-$ критична механічна напруга домену; $\mathrm{X}_{1}$ та $Y_{1}$ - коефіцієнти, що визначаються відповідними значеннями п’єзомодулів.

Беручи до уваги той факт, що $є$ п'єзоелемент $є$ дуже складним електромеханічним елементом, його математичний опис представляє великі складності. Це ускладнюється ще й необхідності врахування коливань та деформацій консольної металевої пластини. Отже в роботі основні результати дослідження отримано експериментальним шляхом.

Для проведення експериментальних досліджень були розроблені дві експериментальні установки: для дослідження вібраційних (рис. 2, а) та акустичних (рис. 2, б) впливів на п’єзоперетворювачі. В роботі були проведені дослідження з п'єзоелементами 14 типів (у вигляді 
кілець та дисків різної товщини та діаметрів) з керамік ЦТС-19 та ЦТС-23, а також з біморфними та консольними металевими пластинами різної товщини та з різних матеріалів [10].

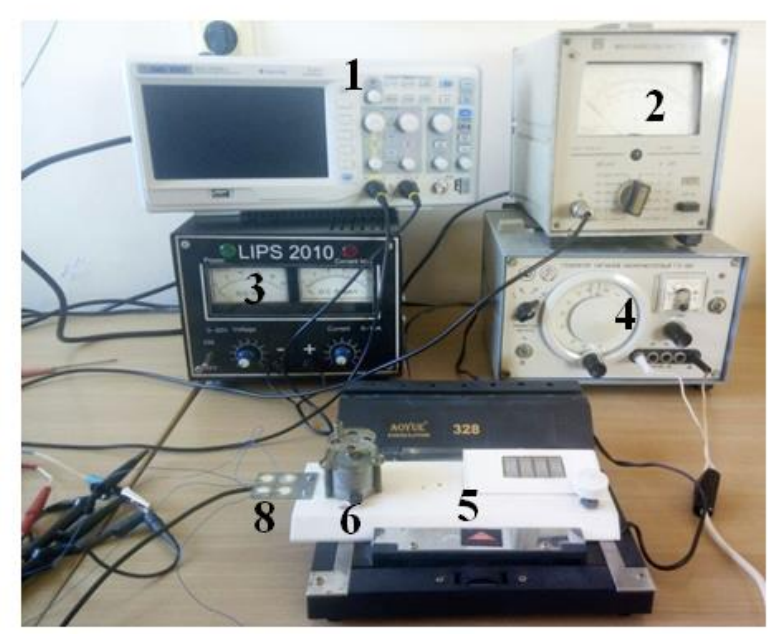

a)

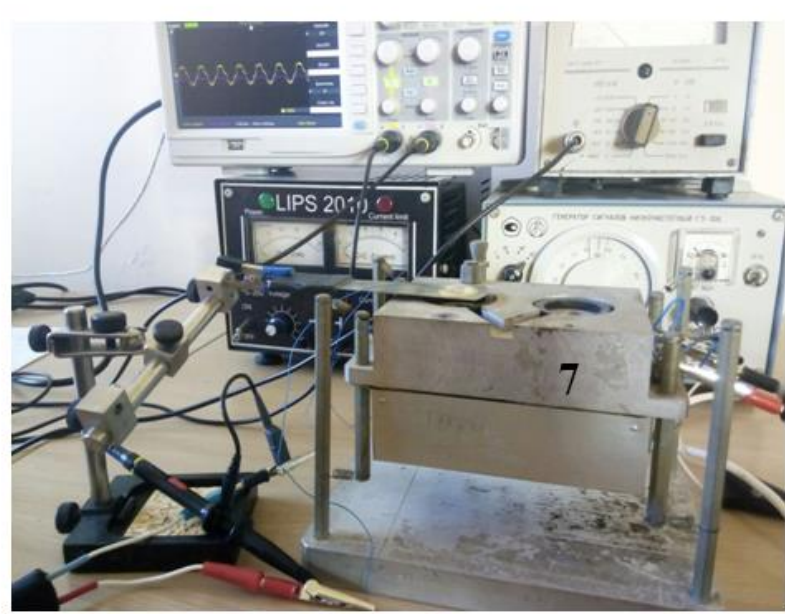

б)

Рис. 2. Загальний вигляд установки для дослідження КДПП при вібраційному (а) та акустичному (б) впливі на п'єзоперетворювачі:

1 -осцилограф $\quad$ SDS1052DL+; 2 -мілівольтметр B3-38; 3 - джерело живлення Lips2010; 4 генератор ГЗ-106; 5 - експериментальна платформа АОYUЕ328; 6 - двигун AMS1141М від Elecrow з асиметричним навантаженням на валу; 7 -пульсофон; 8 -досліджувані асиметричні біморфні п'єзоперетворювачі

Для накопичення енергії було спроектовано та виготовлено плату випрямляча на базі чипу LTC3330, що зображена на рис. 3 [4].

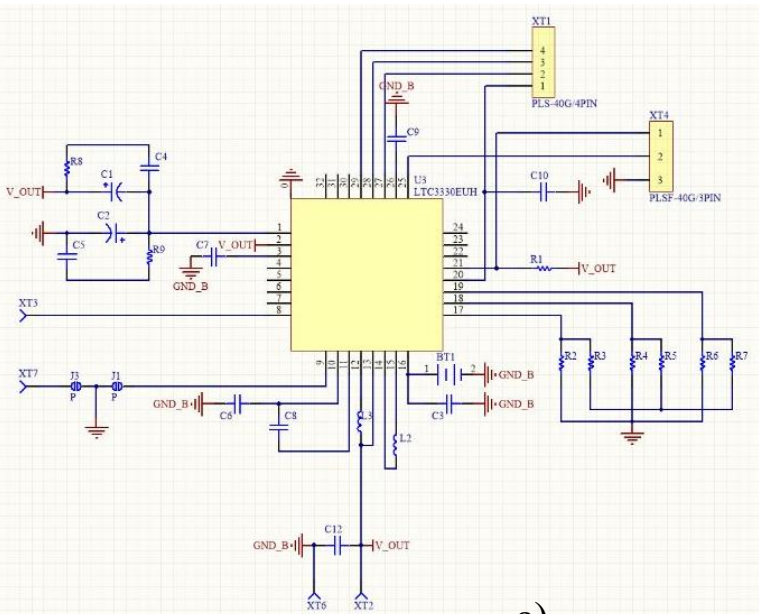

a)

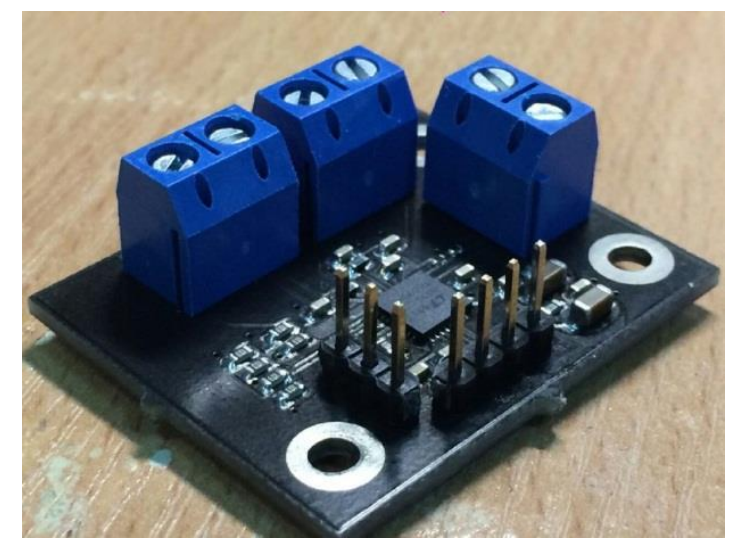

б)

Рис. 3. Схема (а) та виготовлена плата (б) накопичувача енерхії на основі чипу LTC3330 Linear Technology

Схема перетворювача зі схемою випрямлення і накопичення наведена на рис. 4 [1].

В експерименті в якості ПП використані п’єзоелементи 7BВ-12-9 фірми Murata Manufacturing Co. [10], що складаються 3 металевих пластини з латуні діаметром 12 мм та товщиною 0,1 мм із закріпленими на них п'єзоелементами діаметром 9 мм та товщиною 0,12 мм. В якості консольної пластини використана оцинкована стальна пластина марки 08пс/3сп розмірами $35 \times 20 x 0,4$ мм [4]. 
За допомогою складених експериментальних установок були проведені усі необхідні дослідження щодо лінійних розмірів п'єзоелементів та металевих пластин (МП). Так, на рис. 5 та рис. 6 приведені отримані і розраховані за розробленими в роботі [4] залежності рівня вихідного сигналу (нормовані) в залежності від форм та розмірів електродів.

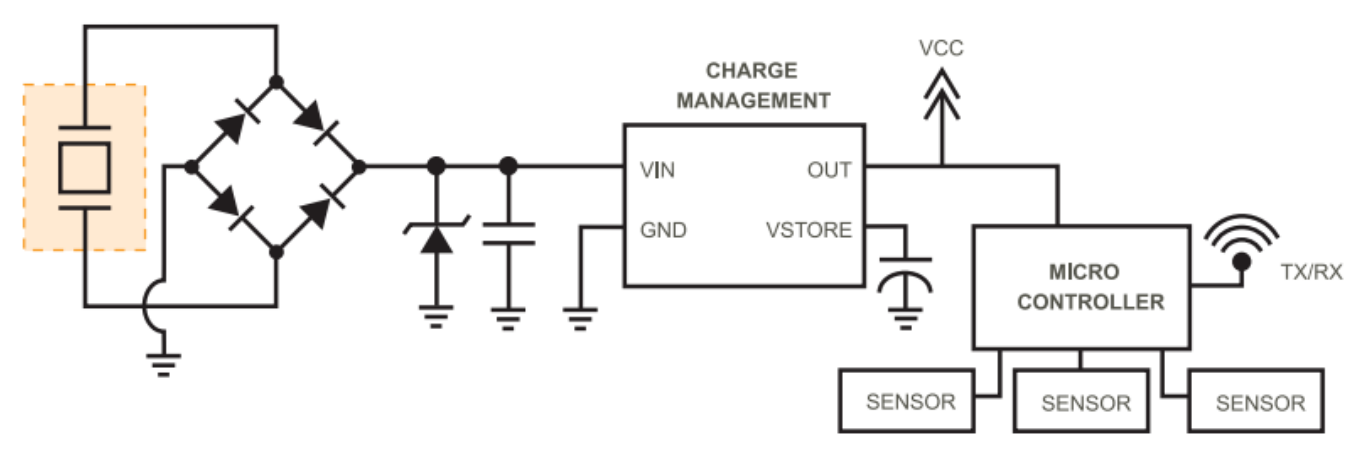

Рис. 4. Схема пристрою накопичення енергї̈ з п'єзоперетворювачем [1]
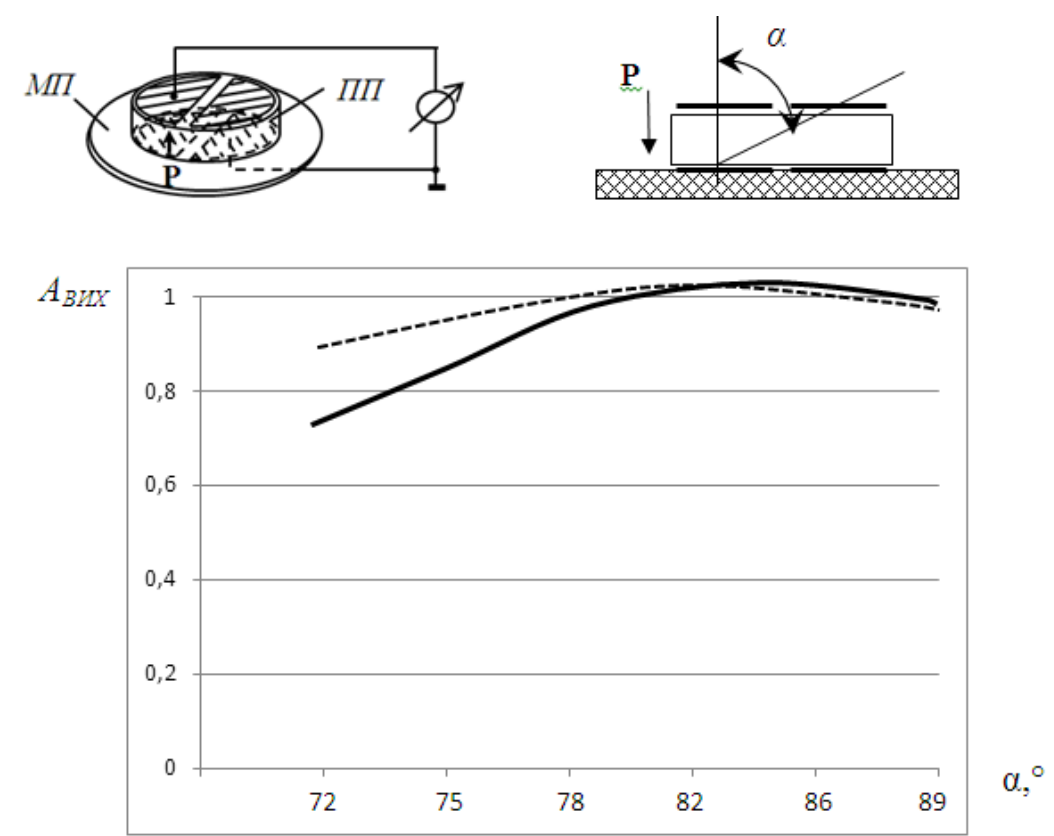

Рис. 5. Розраховані (пунктирна лінія) та експериментально отримані (суцільна лінія) залежності рівнів вихідного сигналу (нормовані) в залежнності від форм та розмірів електродів: МП-металева пластина; ПП - п'єзоперетворювач

На рис. 5 наведено результати дослідження тонких КДПП у формі диска [4]. Зміною розмірів (відповідно й форм) електродів змінюється кут між векторами поляризації $\mathbf{P}$ й напруженості поля між вихідними електродами Е. Як видно з рис. 5, б, крива має свій максимум, тобто рівень вихідного сигналу є максимальним не завжди при перпендикулярних векторах $\mathbf{P}$ та $\mathbf{E}$. Це означає, що при проектуванні конструкцій ПП необхідно враховувати значно більше факторів, а ніж просто забезпечувати перпендикулярність відповідних векторів. Цей результат був підтверджений й на інших подібних експериментах.

На рис. 6 показаний випадок дослідження циліндричних ПП, у яких ПП поляризовані по товщині [4]. Електроди розміщувалися на торцях циліндру, забезпечуючи при цьому майже перпендикулярний кут між векторами $\mathbf{P}$ та $\mathbf{E}$. Зміною розмірів та форм електродів досліджувався вплив кута між основними векторами на рівень вихідного сигналу. Отримані результати підтверджують висновки, що були отримані в попередньому дослідженні. 
Загалом, при проведення усіх досліджень різниця відхилень між експериментальними та теоретичними даними не перевищувала $10 \%$.

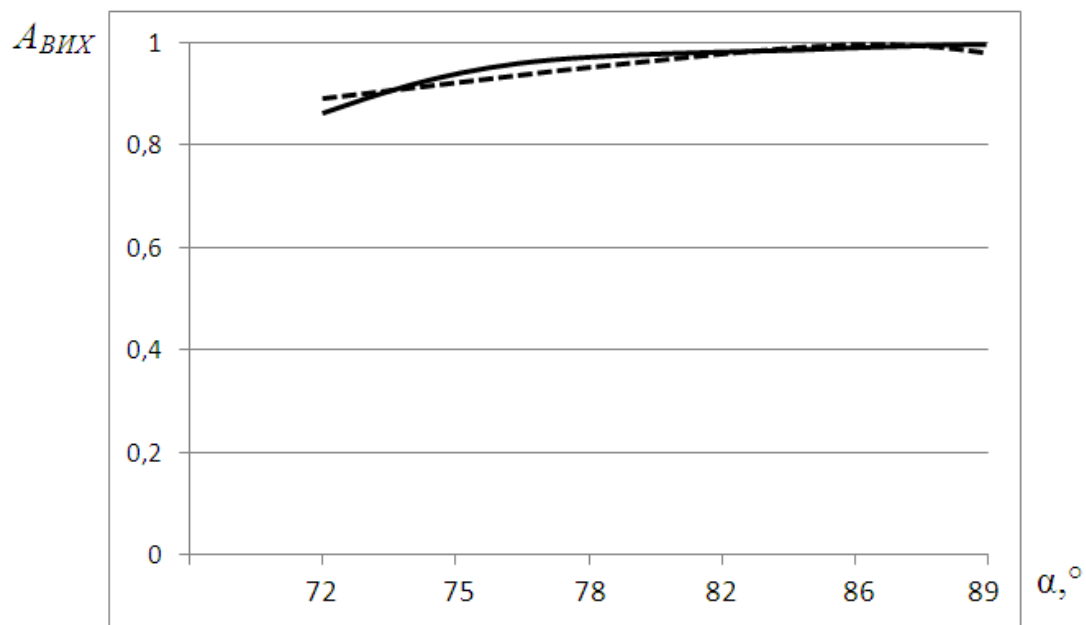

Рис. 6. Розраховані (пунктирна лінія) та експериментально отримані (суцільна лінія) залежності рівнів вихідного сигналу (нормовані) в залежності від форм та розмірів електродів з ПП у формі циліндра

Висновки. Таким чином, в результаті проведення роботи отримані такі результати:

- зібрані експериментальні стенди для дослідження вібраційних та акустичних впливів на КДПП; розроблене власне схемотехнічне рішення накопичувача енергії від ПП на основі чипу LTC3330 Linear Technology, виготовлені зразки;

- за допомогою установок були досліджені різні варіанти виконання конструкції КДПП для визначення параметрів вібрації, досліджені різні схеми під'єднання п'єзоелементів, їх кількість та тип (дослідження проводилися з 14 типами ПП, різними типами біморфних та консольних пластин);

- на основі проведених в роботі досліджень зроблено висновки та надано рекомендації щодо розташування електродів на п'єзокерамічному елементі, тобто щодо забезпечення необхідного кута між векторами $\mathbf{P}$ та $\mathbf{E}$, для досягнення максимального рівня вихідного сигналу.

Список бібліографічного опису.

1. Бугаев В. И. Сборщики энергии вибраций от Mide Technology приходят на смену батарейкам / В. И. Бугаев, В. А. Дидук, М. П. Мусиенко // Новости электроники. Москва. - № 7(141). 2015. С. 23 - 27.

2. Корецька О.О.Доменно-дисипативні п’єзоперетворювачі в конструкціях п’єзомагнітних тахометрів / О.О. Корецька // Матеріали ХХІ Всеукр. наук.-метод. конф «Могилянські читання - 2018», 12-17 листопада 2018. Миколаїв: Вид-во ЧНУ ім. Петра Могили. - 2018. - С. 100-101.

3. Корецька О. О. Методи та засоби підвищення вихідної напруги датчиків, що працюють від енергії вимірювального сигналу / О. О. Корецька // Матеріали ХІХ Всеукр. наук.-метод. конф «Могилянські читання - 2016», 14-18 листопада 2016. Миколаїв: Вид-во ЧНУ ім. Петра Могили. - 2016. - С. 91-93.

4. Корецька О.О. Моделі та засоби побудови енергоефективних ІоТ пристроїв на базі п’єзокерамічних перетворювачів: дис. на отримання наукового ступеня канд. техн. наук: спец. 05.13.05 „Комп’ютерні системи та компоненти" / О. О. Корецька. - Черкаси, 2019. - 154 с.

5. Мусієнко М. П. Консольні п’єзоелектричні накопичувачі вібрації для ІоТ пристроїв / М. П. Мусієнко, О. О. Корецька // Наукові праці: науковий журнал. Серія «Комп’ютерні технології». Вип. 296. Т. 308. Миколаїв: ЧНУ ім. Петра Могили. - 2017. - С. 139-145.

6. Мусиенко М. П. Теоретические основы, методы и средства структурно-энергосилового преобразования на основе полиэлектродных пьезокерамических элементов для систем управления: Диссертация д-ра техн. наук: 05.13.05. - Одесса, 2006. -495 c.

7. Томенко М. Г. Використання консольних п’єзокерамічних ідентифікаторів у вібродіагностиці при визначенні аварійних ситуацій потенційно небезпечних виробництв / М. Г. Томенко, О. О. Корецька // Вісник Черкаського державного технологічного університету. Серія: Технічні науки. 2018. № 4. - Черкаси: ЧДТУ. - С. 68-72. 
8. Томенко М.Г. Підвищення надійності систем раннього визначення аварійності складних технологічних виробництв за допомогою безпровідних автономних п’єзотранспондерів / М. Г. Томенко, О. О. Корецька // Наукові праці: науковий журнал. Серія «Комп’ютерні технології». Вип. 305. Т. 317. - Миколаїв: ЧНУ ім. Петра Могили. 2018. - С. 122126.

9. Шарапов В.М. Пьезоэлектрические датчики / В. М. Шарапов, М. П. Мусиенко, Е. В. Шарапова // Москва: Техносфера, 2006. - 632 c.

10. Murata. Innovator in electronics. 7bb-12-9 [Электронный pecypc] // Веб-сайт магазина muRata. - Режим доступа:URL: https://www.murata.com/products/productdetail? partno=7BB-12-9.

\section{References.}

1. Bugaev, V. I. Vibration energy collectors from Mide Technology replace batteries / V. I. Bugaev, V. A. Diduk, M. P. Musienko, // Novosti elektroniki, No. 7 (141), 2015, Moscow, pp. $23-27$ [in Russian].

2. Koretska O. O. Domens and Dissipative piezotransducers in the piezo-magnetic tachometer designs / O. O. Koretska // Proceedings of XXI Ukrainian Scientific and Methodological Conference "Mohylaynsky Readings - 2018", November 12-17, 2018. Mykolaiv: BSNU. - 2018. - C. 100-101 [in Ukrainian].

3. Koretska O. O. Methods and means of increasing the output voltage of sensors operating from the energy of the measuring signal / O. O. Koretska // Proceedings of XIX Ukrainian Scientific and Methodological Conference "Mohylaynsky Readings - 2016", November 14-18, 2016. Mykolaiv: BSNU. - C. 91-93 [in Ukrainian].

4. Koretska O. O. Models and tools for constructing energy efficient IoT devices based on piezoceramic transdusers: Dissertation for the technical staff. Sciences: 05.13.05. - Cherkasy. - 2019. - $154 \mathrm{p}$ [in Ukrainian].

5. Musiyenko M. P. Console piezoelectric vibration drives for IoT devices / M. P. Musiyenko, O. O. Koretska // Scientific papers: scientific journal. Computer Technology series. No. 296. T. 308. Nikolaev: BSNU. - 2017. - P. 139-145 [in Ukrainian].

6. Musiyenko M. P. Theoretical foundations, methods and means of structural-energy-power conversion based on polyelectrod piezoceramic elements for control systems: the Dissertation of the doctor tehn. sciences: 05.13.05. - Odessa. - 2006. 495 p [in Russian].

7. Tomenko M. G. The use of console piezoceramic identifiers in vibration diagnostics in the identification of potentially hazardous industries / M. G. Tomenko, O. O. Koretska // Bulletin of Cherkasy State Technological University. Series: Technical Sciences. 2018. № 4. Cherkasy: ChSTU. 2018. P. 68-72 [in Ukrainian].

8. Tomenko M. G. Improving the reliability of sophisticated technology early detection systems with wireless stand-alone piezotransponders / M. G. Tomenko, O. O. Koretska // Scientific papers: scientific journal. Computer Technology Series. No. 305. T. 317. Mykolaiv: BSNU. 2018. P. 122-126 [in Ukrainian].

9. Sharapov V. M. Piezoelectric sensors: monograph / V. M. Sharapov, M. P. Musienko, V. V. Sharapova // Ed. V. M. Sharapov. Moscow: Tehnosfera, 2006. 632 p. [in Russian].

10. Murata. Innovator in electronics. 7bb-12-9. URL: https://www.murata.com/products/ productdetail?partno=7BB-12-9. 